CZASOPISMO INŻYNIERII LA¿OWEJ, ŚRODOWISKA I ARCHITEKTURY JOURNAL OF CIVIL ENGINEERING, ENVIRONMENT AND ARCHITECTURE

JCEEA, t. XXXIII, z. 63 (1/II/16), styczeń-marzec 2016, s. 291-298

Dawid RYŚ ${ }^{1}$

Józef JUDYCKI ${ }^{2}$

Piotr JASKULA

\title{
WPŁYW RÓWNOŚCI NAWIERZCHNI I DYNAMICZNEGO ODDZIAŁYWANIA POJAZDÓW CIĘŻKICH NA TRWAŁOŚĆ ZMĘCZENIOWĄ NAWIERZCHNI PODATNYCH
}

\begin{abstract}
Podczas ruchu pojazdu obserwuje się odchylenia nacisków osi pojazdów od nacisku statycznego, co jest spowodowane nierównościami nawierzchni. Dynamiczne obciążenia pojazdów w większym stopniu wytężają konstrukcję nawierzchni drogowej. Rozkład obciążeń dynamicznych ma kształt rozkładu normalnego i jest opisywany poprzez obciążenie statyczne oraz wskaźniki dynamiczne DI lub DLC. Wraz z pogorszeniem równości i zwiększeniem prędkości średniej pojazdów rosną maksymalne siły dynamiczne wywierane przez osie pojazdów, zwiększa się zatem ich oddziaływanie na konstrukcję nawierzchni. Celem artykułu jest ocena, w jaki sposób oddziaływania dynamiczne pojazdów ciężkich wynikające z równości nawierzchni wpływają na trwałość zmęczeniową nawierzchni. W artykule wyprowadzono współczynniki dynamicznego oddziaływania pojazdów $\mathrm{k}_{\mathrm{d}} \mathrm{i}$ podano je w funkcji równości nawierzchni i średniej prędkości ruchu pojazdów. Wykazano, że pogorszenie równości nawierzchni określone zmianą wskaźnika IRI do granicy klasy A, czyli do IRI = 2,0 w przypadku dróg klasy A,S i GP oraz do IRI = 3,0 w przypadku dróg klasy G, powoduje przyrost wartości współczynnika dynamicznego $\mathrm{k}_{\mathrm{d}}$ od $9 \%$ do $16 \%$. Pogorszenie równości nawierzchni do granicy klasy $\mathrm{B}$ (stan zadowalający) powoduje spadek trwałości zmęczeniowej nawierzchni aż o 30\%. Oznacza to, że nadanie dobrej równości początkowej nawierzchni oraz jej utrzymanie w trakcie eksploatacji może istotnie wydłużyć trwałość zmęczeniową konstrukcji nawierzchni.
\end{abstract}

Słowa kluczowe: współczynnik równoważności obciążenia osi, współczynnik obciążenia dynamicznego, wskaźnik równości nawierzchni IRI, oddziaływania dynamiczne, trwałość nawierzchni, ruch ciężki

\footnotetext{
${ }^{1}$ Autor do korespondencji/corresponding author: Dawid Ryś, Politechnika Gdańska, ul. Narutowicza 11/12 80-233 Gdańsk, (58) 347 2782, dawid.rys@ wilis.pg.gda.pl

2 Józef Judycki, Politechnika Gdańska, jozef.judycki@ wilis.pg.gda.pl

${ }^{3}$ Piotr Jaskuła, Politechnika Gdańska, piotr.jaskula@ wilis.pg.gda.pl
} 


\section{Wstęp}

\subsection{Zarys problemu}

Podczas ruchu pojazdu obserwuje się odchylenia nacisków osi pojazdów od nacisku statycznego, co jest spowodowane nierównościami nawierzchni. Dynamiczne obciążenia pojazdów w większym stopniu wytężają konstrukcje nawierzchni drogowej, obiektów inżynierskich oraz innych elementów infrastruktury drogowej. Wyniki pomiarów dynamicznych nacisków osi podane są m.in. w publikacjach [1], [2], [5]. Zgodnie z badaniami przeprowadzonymi przez Glilespie i wsp. [5] wartość oczekiwana rozkładu prawdopodobieństwa przeważnie pokrywa się z naciskiem statycznym osi. Współczynnik obciążenia dynamicznego DLC (ang. „Dynamic Load Coefficient”) oznacza wskaźnik zmienności dynamicznych nacisków osi i jest miarą charakteryzującą rozkład prawdopodobieństwa dynamicznych nacisków osi i jest opisany wzorem:

$$
D L C=\frac{\sigma}{\overline{\mathrm{F}}}
$$

gdzie: $\sigma$ - odchylenie standardowe siły nacisku osi, $\overline{\mathrm{F}}$ - średnia wartość siły nacisku osi w przybliżeniu równa naciskowi statycznemu.

W literaturze występuje również inna miara wyrażająca dynamiczne obciążenia osi: wskaźnik wpływu dynamicznego (ang. „Dynamic Impact Factor”) DI [2], [5], [7], który opisany jest wzorem:

$$
D I=1+\mathrm{Z}_{\mathrm{r}} D L C
$$

gdzie: $\mathrm{Z}_{\mathrm{r}}$ - kwantyl rozkładu normalnego.

Wraz ze wzrostem wskaźników DLC i DI rosną maksymalne dynamiczne obciążenia przekazywane przez pojazd na nawierzchnie. Na wartość współczynników DLC i DI wpływ mają charakterystyka zawieszenia, prędkość pojazdu i równość nawierzchni.

W badaniach Gillespie i wsp [5] przeprowadzono m.in. analizę wpływu rodzaju zawieszenia na trwałość nawierzchni podatnych, z której wynika, że pojazdy wyposażone w zawieszenie klasyczne (z resorami piórowymi) wywołują większą szkodę zmęczeniową nawierzchni wyrażoną spękaniami zmęczeniowymi niż pojazdy wyposażone $\mathrm{w}$ zawieszenie pneumatyczne. W przypadku deformacji trwałych wpływ rodzaju zawieszenia i obciążeń dynamicznych z nim związanych jest pomijalnie mały. Wpływ rodzaju zawieszenia był również przedmiotem analiz prowadzonych $w$ ramach projektu DIVINE [4], zgodnie $\mathrm{z}$ którymi nawierzchnie obciążone ruchem pojazdów wyposażonych $\mathrm{w}$ zawieszenia klasyczne ulegają uszkodzeniom w czasie o $15 \%$ krótszym niż nawierzchnie obciążone pojazdami z zawieszeniem pneumatycznym.

Sweatman [11] badał wpływ równości nawierzchni i prędkości pojazdów na współczynnik DLC przy różnych systemach zawieszenia pojazdów. Z badań 
tych wynika, że współczynnik DLC rośnie wraz ze wzrostem prędkości, co jest również potwierdzone badaniami Gillespie i wsp.[5]. Jak wynika z studiów literatury [1], [2], [5], [7], [10], [11] wraz z pogorszeniem równości (zwiększeniem wartości wskaźnika IRI) rosną wskaźniki DLC i DI, czyli rosną dynamiczne obciążenia wywierane przez osie pojazdów na nawierzchnie.

Stan i parametry zawieszenia pojazdów, mimo że znacząco wpływają na oddziaływania dynamiczne, są praktycznie niemożliwe do kontrolowania na drodze. Ograniczenie prędkości pojazdów ze względu na oddziaływania dynamiczne nie przyniesie rezultatu ponieważ przy mniejszych prędkościach ruchu maleją moduły sztywności warstw asfaltowych i nawierzchnia jest bardziej wytężana. Jedynym parametrem, który ma istotny wpływ na oddziaływania dynamiczne pojazdów a który może być kontrolowany i ulepszany jest równość nawierzchni. Prawidłowa równość nawierzchni nowych jest uzyskiwana dzięki staranności wykonania robót. Równość jest tym elementem, który nie zwiększa kosztów realizacji inwestycji drogowej, a który może istotnie zwiększyć trwałość konstrukcji nawierzchni lub zmniejszyć ryzyko powstania przedwczesnych uszkodzeń poprzez zmniejszenie oddziaływań dynamicznych pojazdów.

\subsection{Cel artykułu}

Celem artykułu jest ocena, w jaki sposób oddziaływania dynamiczne pojazdów ciężkich wynikające z równości nawierzchni, mierzonej wskaźnikiem IRI, wpływają na trwałość zmęczeniową nawierzchni.

\section{Wpływ równości nawierzchni i prędkości pojazdów na dyna- miczne oddziaływanie pojazdów}

\subsection{Stan równości dróg w Polsce}

Równość podłużna nawierzchni wyrażona jest za pomocą wskaźnika IRI (ang. „International Roughness Index”). W wytycznych stosowania systemu Diagnostyki Stanu Nawierzchni (DSN) [3] określono wymagania co do miarodajnej równości nawierzchni i podano je w tablicy 1.

Tablica 1. Klasyfikacja stanu nawierzchni na podstawie wskaźnika równości IRI według polskiego systemu DSN, na podstawie [3]

Table 1. Classification of pavement condition on the bases of IRI index on the bases of polish DSN system, based on [3]

\begin{tabular}{|c|l|c|c|}
\hline \multirow{2}{*}{ Klasa } & \multirow{2}{*}{ Ocena stanu nawierzchni } & \multicolumn{2}{|c|}{$\begin{array}{c}\text { Miarodajna równość podłużna wyrażona przez } \\
\text { IRI [mm/m] }\end{array}$} \\
\cline { 3 - 4 } & & \multicolumn{2}{|c|}{ Klasa drogi } \\
\cline { 3 - 4 } & & $\mathrm{A}, \mathrm{S}, \mathrm{GP}$ & $\mathrm{G}$ \\
\hline $\mathrm{A}$ & Stan dobry & $<2,0$ & 3,0 do 5,0 \\
\hline B & Stan zadowalający & 2,0 do 4,3 & 5,1 do 6,6 \\
\hline C & Stan niezadowalający & 4,4 do 5,7 & $>6,6$ \\
\hline D & Stan zły & $>5,7$ & \\
\hline
\end{tabular}


Aktualne wyniki oceny stanu technicznego nawierzchni (2015 rok), dotyczące równości podłużnej wskazują, że na drogach krajowych $75 \%$ długości odcinków jest w stanie dobrym (klasa A) a $22 \%$ w stanie zadowalającym. Mniej niż $4 \%$ odcinków jest w stanie niezadowalającym bądź złym [8]. Od kilku lat równość nawierzchni na drogach krajowych ulega poprawie, dzięki wielu remontom i nowym inwestycjom. Jest rzeczą pewną, że stan równości dróg wojewódzkich, powiatowych i gminnych jest gorszy niż dróg krajowych, brakuje jednak danych z pomiarów równości nawierzchni na tych drogach.

\subsection{Prędkość samochodów ciężarowych}

Prędkość pojazdów, podobnie jak równość nawierzchni, istotnie wpływa na oddziaływania dynamiczne oraz na wskaźniki DI i DLC. Typowo dopuszczalna prędkość samochodów ciężarowych w Polsce poza obszarem zabudowania wynosi od $70 \mathrm{~km} / \mathrm{h}$ na drogach jednojezdniowych dwupasowych do $80 \mathrm{~km} / \mathrm{h}$ na drogach dwujezdniowych, drogach ekspresowych i autostradach. Na podstawie ciągłych pomiarów prędkości w ruchu pojazdów można przyjąć, że na autostradach i drogach ekspresowych średnia prędkość pojazdów ciężkich wynosi $90 \mathrm{~km} / \mathrm{h}$, natomiast na pozostałych drogach $70 \mathrm{~km} / \mathrm{h} \mathrm{[6].}$

\subsection{Współczynnik dynamiczny oddziaływania osi pojazdów}

$\mathrm{W}$ analizach prezentowanych w niniejszym artykule zastosowano amerykańskie modele dynamicznego obciążenia nawierzchni pojazdami ciężkimi wyznaczone w raporcie [7]. Współczynnik DI w zależności od prędkości pojazdu i równości nawierzchni został opisany w pracy [7] następującym modelem:

$$
D I=1+\alpha \cdot V \cdot I R I
$$

gdzie: $\alpha=0,0017$ - parametr dla przyjętego w analizie modelu „quatercar", $\mathrm{V}$ - średnia prędkość pojazdów [km/h], IRI - wskaźnik równości nawierzchni $[\mathrm{mm} / \mathrm{m}]$

Wartości wskaźnika wpływu dynamicznego DI przeliczono na wskaźniki zmienności dynamicznych nacisków osi DLC, przekształcając zależność 2:

$$
D L C=\frac{D I-1}{Z r}=\frac{\sigma}{\text { Qstat }}
$$

gdzie: DI - wskaźnik wpływu dynamicznego, wg modelu (3), $Z_{\mathrm{r}}$ - kwantyl rozkładu normalnego, $\mathrm{Z}_{\mathrm{r}}=2$ zgodnie $\mathrm{z}$ [7], $\mathrm{Q}_{\text {stat }}$ - siła nacisku statycznego osi w przybliżeniu równa średniej z nacisków dynamicznych, $\sigma$ - odchylenie standardowe dynamicznych nacisków osi.

Rozkład dynamicznych nacisków osi zdefiniowany jest poprzez obciążenie statyczne $\mathrm{Q}_{\text {stat }}$ oraz jeden ze wskaźników: DI lub DLC. Siły nacisku dynamicznego przeliczono na współczynnik równoważności obciążenia osi, które wyrażają oddziaływanie pojazdu na konstrukcję nawierzchni. Do obliczenia współ- 
czynników równoważności zastosowano wzór czwartej potęgi. Średni współczynnik równoważności obciążenia dynamicznego osi obliczono w sposób dyskretny na podstawie funkcji gęstości prawdopodobieństwa rozkładu normalnego obciążeń dynamicznych osi, zgodnie ze wzorem (5).

$$
F_{d y n}=\sum_{i=1}^{n}\left(\frac{Q d y n_{i}}{Q_{s}}\right)^{4} p_{i}
$$

gdzie: $\mathrm{F}_{\mathrm{dyn}}$ - współczynnik równoważności obciążenia pojazdu z uwzględnieniem oddziaływań dynamicznych, $\mathrm{Qdyn}_{\mathrm{i}}$ - obciążenie dynamiczne osi i, występujące $\mathrm{z}$ określonym prawdopodobieństwem $\mathrm{p}_{\mathrm{i}}$, przy czym sumowanie przeprowadza się do określonego poziomu istotności $\alpha(\mathrm{p}<\alpha), \mathrm{Q}_{\mathrm{s}}-$ obciążenie standardowe osi $\mathrm{Q}_{\mathrm{s}}=100 \mathrm{kN}, \mathrm{n}$ - liczba przyjętych przedziałów obciążenia dynamicznego w obrębie określonego poziomu istotności $\alpha$.

Ponieważ rozkład obciążeń dynamicznych jest rozkładem normalnym to równanie (5) można przekształcić w następujący sposób:

$$
\begin{array}{r}
F_{d y n}=\sum_{i=1}^{n}\left(\frac{Q d y n_{i}}{Q_{s}}\right)^{4} p_{i}=\sum_{i=1}^{n}\left(\frac{Q s t a t+\mu_{i} \cdot D L C \cdot Q s t a t}{Q_{s}}\right)^{4} p_{i} \\
=\left(\frac{Q s t a t}{Q s}\right)^{4} \cdot \sum_{i=1}^{n}\left(1+\mu_{i} \cdot D L C\right)^{4} p_{i}=k_{d}\left(\frac{Q s t a t}{Q s}\right)^{4}
\end{array}
$$

gdzie: $\mu_{\mathrm{i}}$ - kwantyl rozkładu normalnego dla określonego prawdopodobieństwa $\mathrm{p}_{\mathrm{i}}$, który może przyjmować wartości dodatnie i ujemne, przy czym $(\mathrm{p}<\alpha)$, gdzie $\alpha$ oznacza przyjęty poziom istotności (przyjęto $\alpha=96 \%$ ), $\mathrm{k}_{\mathrm{d}}-$ współczynnik dynamicznego oddziaływania osi na nawierzchnię, pozostałe oznaczenia jak wyżej. Należy zaznaczyć, że współczynnik $\mathrm{k}_{\mathrm{d}} \mathrm{w}$ równaniu (6) nie zależy od obciążenia danej osi, ale od współczynnika dynamicznego obciążenia DLC oraz od przyjętego poziomu prawdopodobieństwa $\alpha$.

\section{Analiza wpływu równości nawierzchni i prędkości pojazdu na trwałość nawierzchni}

W oparciu o równanie (6) i równanie (3) określono zależności między wskaźnikiem IRI a współczynnikiem oddziaływania dynamicznego pojazdów $\mathrm{k}_{\mathrm{d}}$ dla czterech prędkości średnich pojazdów ciężkich. Wynik przedstawiono na rys. $1 \mathrm{~A}$.

Do określenia wpływu dynamicznego oddziaływania pojazdów na skrócenie trwałości zmęczeniowej nawierzchni zastosowano współczynnik DFL (od ang. „Decrease of Fatigue Life”, który został wyprowadzony w publikacji [9], a na potrzeby niniejszego artykułu został przekształcony w następujący sposób: 

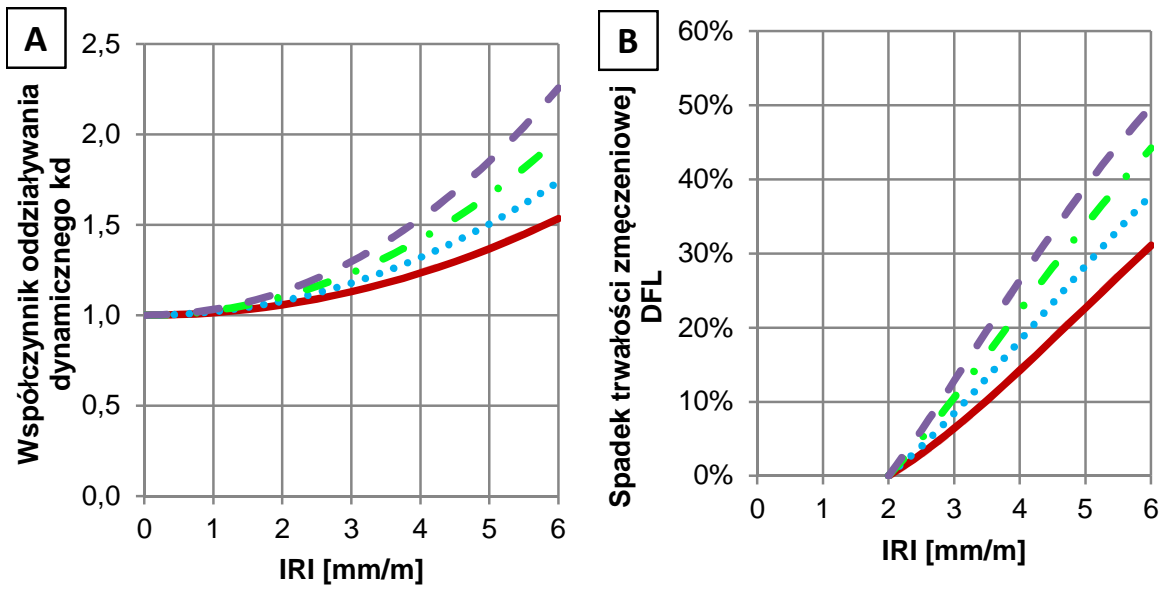

Średnia prędkość

$70 \mathrm{~km} / \mathrm{h}-.80 \mathrm{~km} / \mathrm{h}--90 \mathrm{~km} / \mathrm{h}$

Rys. 1. Wpływ równości i prędkości pojazdów na A) współczynnik dynamicznego oddziaływania $\mathrm{k}_{\mathrm{d}}$ B) spadek trwałości nawierzchni

Fig. 1. Impact of road roughness and vehicle speed on: A) dynamic impact coefficient $k_{d}$ B) decrease of fatigue life of pavement structure

$$
D F L(\%)=\left(1-\frac{F_{d y n, I R I p}}{F_{d y n, I R I}}\right)=\left(1-\frac{k_{d, I R I p} \cdot F_{\text {stat }}}{k_{d, I R I} \cdot F_{\text {stat }}}\right)=\left(1-\frac{k_{d, I R I p}}{k_{d, I R I}}\right)
$$

gdzie: $\mathrm{F}_{\mathrm{dyn}, \mathrm{IRI}}, \mathrm{F}_{\mathrm{dyn}, \mathrm{IRI}}$ - dynamiczny współczynnik równoważności obciążenia osi przy równości nawierzchni odpowiednio IRIp i IRI, $\mathrm{F}_{\text {stat }}$ - statyczny współczynnik równoważności obciążenia osi, $\mathrm{k}_{\mathrm{d}, \mathrm{RRIp}}$, $\mathrm{k}_{\mathrm{d}, \mathrm{IRI}}$ - współczynniki oddziaływania dynamicznego dla równości nawierzchni odpowiednio IRIp i IRI, IRIp porównawcza wartość wskaźnika równości nawierzchni (przyjęto IRIp=2,0), IRI - średnia wartość wskaźnika równości nawierzchni.

Współczynnik DFL określa o ile procent zmniejszy się trwałość zmęczeniowa nawierzchni względem nawierzchni o dobrej równości, jeżeli równość nawierzchni pogorszy się. Poziom równości porównawczej IRIp $=2,0[\mathrm{~mm} / \mathrm{m}]$ przyjęto jako granicę klasy równości A (bardzo dobrej) dla autostrad. Jeżeli przyjęto by inny poziom porównawczy, np. IRIp $=1,0[\mathrm{~mm} / \mathrm{m}]$ to wskaźnik DFL wzrósłby o kilka procent. Zależność wskaźnika DFL od współczynnika IRI przedstawiono na rysunku $1 \mathrm{~B}$.

Dla bardzo równych nawierzchni (IRI $\leq 1 \mathrm{~mm} / \mathrm{m}$ ) współczynnik dynamiczny $\mathrm{k}_{\mathrm{d}}$ bliski jest jedności $\mathrm{i}$ wraz $\mathrm{z}$ pogorszeniem równości (przyrostem IRI) współczynnik dynamiczny $\mathrm{k}_{\mathrm{d}}$ znacznie się zwiększa (rys. 1A). Oznacza to, że dla bardzo równych nawierzchni wpływ oddziaływania pojazdu z uwzględnieniem efektów dynamicznych jest taki, jak z uwzględnieniem wyłącznie obciążeń statycznych. Wraz z utratą równości, nawierzchnia jest bardziej wytężana na skutek dynamicznego obciążenia pojazdów. Warto zaznaczyć, że równość nawierzchni w trakcie eksploatacji ulega pogorszeniu i zwiększają się oddziaływania dynamiczne pojazdów, co dodatkowo przyspiesza wyczerpanie trwałości nawierzchni. 
Wymagana równość IRI na nowych drogach wynosi poniżej $1,3 \mathrm{~mm} / \mathrm{m}$ na drogach klasy A, S, GP i $1,7 \mathrm{~mm} / \mathrm{m}$ na drogach klasy G. Wymagania dla dróg niższych klas nie są określone. W praktyce maksymalną równość uzyskuje się na poziomie $\mathrm{IRI} \approx 1,0$. Zmiana równości $\mathrm{w}$ obrębie dopuszczalnych granic klasy równości A, czyli z IRI $=1,0$ do $I R I=2,0[\mathrm{~mm} / \mathrm{m}]$ dla dróg klasy A, S i GP, oraz z IRI $=1,0$ do IRI $=3,0[\mathrm{~mm} / \mathrm{m}]$ dla dróg klasy $\mathrm{G}$, spowoduje wzrost współczynnika dynamicznego odpowiednio $\mathrm{z} \mathrm{k}_{\mathrm{d}}=1,03$ do $\mathrm{k}_{\mathrm{d}}=1,13$, czyli o 9\% (drogi klasy A, $\mathrm{S}$ GP) i z k $\mathrm{d}_{\mathrm{d}}=1,02$ do $\mathrm{k}_{\mathrm{d}}=1,18$, czyli o $16 \%$ (drogi klasy G) Zapewnienie wysokiej równości początkowej nawierzchni istotnie wydłuży jej trwałość i jest szczególnie ważne, gdy przewiduje się duże prędkości ruchu pojazdów, czyli na autostradach i drogach ekspresowych.

$\mathrm{Z}$ rysunku $1 \mathrm{~B}$ wynika, że utrata równości nawierzchni do granicy klasy B powoduje spadek trwałości nawierzchni aż o 30\%. Zmiana klasy równości oznacza zmianę IRI z 2,0 na 4,3 [mm/m] dla dróg klasy A, S i GP i prędkości v= $90 \mathrm{~km} / \mathrm{h}$, oraz z 2,0 do $5,0[\mathrm{~mm} / \mathrm{m}]$ dla dróg klasy $\mathrm{G}$ i prędkości v= $70 \mathrm{~km}$. Zależność uwidacznia jak ważnym elementem $w$ trwałości całej konstrukcji nawierzchni jest jej równość. Utrata równości podłużnej istotnie skróci trwałość nawierzchni. Z drugiej strony utrzymanie dobrej równości nawierzchni w trakcie eksploatacji istotnie spowolni proces jej degradacji.

\section{Podsumowanie}

Dynamiczne obciążenia przekazywane przez osie pojazdów na nawierzchnie mają rozkład normalny, w którym wartość oczekiwana równa jest obciążeniu statycznemu a odchylenie standardowe zależy od takich czynników jak równość nawierzchni, prędkość pojazdu i parametry zawieszenia. Przyrost wartości odchylenia standardowego, czyli także przyrost wartości wskaźników DI i DLC, skutkuje wywieraniem większych sił nacisku przez osie pojazdów, a w konsekwencji zwiększeniem oddziaływania pojazdu na nawierzchnie. Wprowadzony w niniejszym artykule współczynnik oddziaływania dynamicznego $\mathrm{k}_{\mathrm{d}}$ istotnie zależy od równości nawierzchni. Pogorszenie równości nawierzchni określone zmianą wskaźnika IRI do granicy klasy A, czyli do IRI = 2,0 w przypadku dróg klasy A,S i GP oraz do IRI $=3,0 \mathrm{w}$ przypadku dróg klasy $\mathrm{G}$, powoduje przyrost wartości współczynnika dynamicznego $k_{d}$ od $9 \%$ do $16 \%$. Pogorszenie równości nawierzchni do granicy klasy B (stan zadowalający) powoduje spadek trwałości zmęczeniowej nawierzchni aż o 30\%. Oznacza to, że nadanie dobrej równości początkowej nawierzchni oraz jej utrzymanie w trakcie eksploatacji może istotnie wydłużyć trwałość zmęczeniową konstrukcji nawierzchni.

\section{Literatura}

[1] Cebon D., Winkler Ch.: A study of road damage due to dynamic wheel loads using a load measuring mat. Raport techniczny nr UMTRI-90-13, 1990.

[2] Cebon D.: Handbook of Vehicle-Road Interaction, Swets \& Zeitlinger, 1999. 
[3] Diagnostyka Stanu Nawierzchni i jej Elementów, Wytyczne Stosowania. Załącznik do zarządzenia nr 34 Generalnego Dyrektora Dróg Krajowych I Autostrad z dnia 30.04.2015. Dostępny w Internecie: www.gddkia.gov.pl/pl/2982/Diagnostyka-Stanu-Nawierzchni.

[4] Dynamic Interaction between vehicles and infrastructure experiment (DIVINE project). Raport techniczny nr DSTI/DOT/RTR/IR6(98)1/FINAL, OECD, Paryż 1998.

[5] Gillespie T.D., Karamihas S.M., Sayers M., Nasim M. A., Hansen W., Ehsan N., Cebon D.: Effects of heavy vehicles characteristic on pavement response and performance. Final Report, The University of Michigen, NCHRP, 1992.

[6] Judycki J., Jaskuła P, Pszczoła M., Jaczewski M., Ryś D., Alenowicz J., Dołżycki B., Stienss M.: Analizy i projektowanie konstrukcji nawierzchni podatnych i półsztywnych. WKŁ, Warszawa, 2014.

[7] Misaghi S., Nazarian S., Carrasco C. J.: Impact of Truck Suspension and Road Roughness on Loads Exerted to Pavements, The University of Texas, FHWA, El Paso 2010 r.

[8] Radzikowski M., Foryś G., Bogdaniuk M.: Raport o stanie technicznym nawierzchni sieci dróg krajowych na koniec 2015 roku. GDDKiA, Warszawa, 2016. Dostępny w Internecie: www.gddkia.gov.pl/pl/2990/Raporty.

[9] Ryś D., Judycki J., Jaskuła P.: Analysis of effect of overloaded vehicles on fatigue life of flexible pavements based on weigh in motion (WIM) data. International Journal of Pavement Engineering, Volume 17, Issue 8, 2016, pp. 716-726. DOI: 10.1080/10298436.2015.1019493.

[10] Shi X.M., Cai C. S.: Simulation of dynamic effects of vehicles on pavement using a 3D interaction model. Journal of Transportation Engineering, s. 135:736-744, ASCE, 2009.

[11] Sweatman, P.F.: A Study of dynamic wheel forces in axle group suspensions of heavy vehicles. Australian Road Research Board, Australia 1983.

\title{
INFLUENCE OF ROAD ROUGHNESS AND DYNAMIC EFFECTS OF COMMERCIAL VEHICLES ON FATIGUE LIFE OF FLEXIBLE PAVEMENTS
}

\begin{abstract}
S u m m a r y
Axle loads varies during motion of vehicle what is a consequence of road roughness and speed. Dynamic loads of vehicles much more strain pavement structure. The dynamic axle loads have a normal distribution and it is described by static load and dynamic factors DI or DLC. The maximum dynamic loads increase with the loss of road roughness and with the increase of average vehicle speed. In consequence the dynamic effects on pavement structure increase. The objective of the article is to assess how the dynamic effects impact on pavement fatigue life. The paper presents the derivation of formula for dynamic effects factor $k_{d}$. The formula depends on road roughness and vehicle speed. It was revealed that the increase of IRI to 2,0 for road technical classes A, S and GP and to 3,0 for road technical class $\mathrm{G}$, causes the increase of dynamic effect factor $\mathrm{k}_{\mathrm{d}}$ by $9 \%$ to $16 \%$, despite that the pavement is in the class of excellent roughness A. Further decrease of road roughness to the critical value of class B (acceptable roughness) causes decrease of pavement fatigue life up to 30\%. It means that high initial roughness and its further maintenance during exploitation significantly increase the pavement fatigue life.
\end{abstract}

Keywords: Load equivalency factors, dynamic load coefficient, international roughness index IRI, dynamic loads, fatigue life of pavement, traffic

Przestano do redakcji: 07.06.2016 $r$.

Przyjęto do druku: 30.06.2016 r.

DOI: $10.7862 / r b .2016 .87$ 